\title{
Introduzindo a geometria fractal no ensino médio: uma abordagem baseada nas formas dosobjetos construídos pela natureza
}

\section{Introducing fractal geometry in high school: an approach based on the shapes of objects built by nature}

DOI: 10.46814/lajdv3n5-014

Recebimento dos originais: 01/05/2021

Aceitação para publicação: 31/06/2021

\author{
Alceu Domingues Alves \\ UPE - FFPNM - UNIVERSIDADE DE PERNAMBUCO, \\ E-mail: aaalllceu@yahoo.com.br \\ Josinalva Estacio Menezes \\ Programa de Pós-Graduação em Ensino das Ciências- UFRPE \\ E-mail: jomene@ded.ufrpe.br
}

\section{Romildo de Albuquerque Nogueira}

Programa de Pós-Graduação em Ensino das Ciências- UFRPE

R. Dom Manuel de Medeiros, s/n. Dois Irmãos. CEP: 52171-900. Recife. PE

E-mail: nogromildo@gmail.com

\section{RESUMO}

A Geometria Fractal é um tema que tem sido pouco explorado nos ensinos fundamental e médio, apesar da sua extrema utilidade na descrição das formas construídas pela natureza. O objetivo geral desse trabalho foi propor e analisar estratégias didáticas para ensinar a geometria fractal, no ensino fundamental e médio, a partir da observação dos objetos e fenômenos naturais e criados pelo homem. Apesar da perfeita adequação das estratégias didáticas propostas a todo ensino básico a amostra trabalhada foi constituída de só por alunos de uma turma de terceiro ano do ensino médio de uma escola pública da rede oficial de ensino do Estado de Pernambuco. A teoria dos construtos pessoais de Kelly foi o método usado na realização da pesquisa. Os resultados obtidos sugerem que os estudantes ampliaram seus construtos pessoais em função da intervenção didática proposta e que é possível introduzir no ensino médio a geometria fractal.

Palavras-chave: Geometria Euclidiana, Geometria Fractal, Construtos pessoais, Ciclo da experiência de Kelly.

\footnotetext{
ABSTRACT

Fractal Geometry is a topic that has been little explored in elementary and high schools, despite its extreme usefulness in describing the shapes built by nature. The general objective of this work was to propose and analyze didactic strategies to teach fractal geometry, in elementary and high school, based on the observation of natural and man-made objects and phenomena. Despite the perfect adequacy of the proposed didactic strategies to all basic education, the studied sample consisted of only students from a third-year high school class in a public school in the official teaching network in the State of Pernambuco. Kelly's personal constructs theory was the method used in conducting the research. The results obtained suggest that students expanded their personal constructs as a result of the proposed didactic intervention and that it is possible to teach fractal geometry in high school.
} 
Palavras-chave: Geometria Euclidiana, Geometria Fractal, Construtos pessoais, Ciclo da experiência de Kelly

\section{INTRODUÇÃO}

Educar na perspectiva dos PCNEM (BRASIL, 1999) exige do educador além do domínio de conteúdos específicos, a capacidade para criar no dia-a-dia da sala de aula situações concretas que permitam o educando aplicar seus conhecimentos. Neste contexto, pretende-se neste capitulo sugerir estratégias para introduzir e avaliar o ensino da geometria fractal no ensino básico, com uma abordagem baseada nas formas dos objetos construídos pela natureza e pelo homem. A discussão sobre a introdução da geometria fractal no ensino básico tem sido proposta tanto no ensino fundamental ( SILVA et al., 2017) como no ensino médio ( SULEIMAN, 2019). A geometria fractal permite a descrição de maneira adequada dos objetos naturais, e, portanto, abre novas possibilidades para entender a complexidade inerente a dinâmica envolvida na construção desses objetos. Em decorrência da ubiquidade dos fractais, livros em diferentes áreas do conhecimento tem utilizado essa geometria na descrição de formas e na dinâmica de processos. Entre os vários livros pode-se citar: Fractals and Chaos Simplified for the Life Sciences (LIEBOVITCH, 1998); Fractal Physiology (BASSINGTHWAIGHTHE et al., 1994; Fractals Everywhere (BARNSLEY, 1993); Fractals (FEDER, 1988). A geometria fractal pode ser pensada como uma linguagem matemática que descreve, analisa e modela as formas encontradas na natureza (JANOS, 2008). O termo "Fractal" tem origem na palavra latina "fractus", que significa quebrado,irregular. Benoit Mandelbrot é reconhecido mundialmente como o "criador" da Teoria dos Fractais. Tal reconhecimento foi devido a publicaçao das suas obras clássicas: Objetos Fractais: Forma, Acaso e Dimensão (1998) e a Geometria Fractal da Natureza (1982).

Os objetos fractais são caracterizados por suas propriedades, que são:

i) a auto-similaridade, a qual significa que partes de um objeto ou processoparece com o objeto ou processo todo;

ii) a dependência de escala (scaling), que significa dizer que a medida dagrandeza depende da escala na qual foi medida;

iii) dimensão fractal, a qual provê uma descrição quantitativa da auto-similaridade e dependência de escala. 
A auto-similaridade da forma geométrica desses objetos não é descrita por uma função algébrica, porém ao invés disto é especificada por meio de um algoritmo que instrui como construir o objeto fractal.

Apesar de ser, atualmente, bem aceito por alguns professores de matemática e ciências a necessidade de ser ensinado no ensino básico (fundamental e médio) a geometria fractal, existe ainda dificuldades metodológicas para o professor trabalhar com a geometria fractal nesses níveis de ensinos.

Com base no exposto propomos como questão de pesquisa nesse trabalho: como trabalhar com os alunos do ensino básico a geometria fractal?

Desta forma, o objetivo geral da presente pesquisa foi propor e analisar estratégias didáticas para ensinar a geometria fractal, no ensino básico, a partir da observação dos objetos criados pelo homem e pela natureza. É interessante observar que o presente texto não tem como foco a construção de objetos fractais e suas propriedades, um tema já abordado em outras publicações, porém a grande questão que estamos propondo é a busca de estratégias adequadas para ensinar a geometria fractal no ensino básico. Assim, para se investigar o desenvolvimento das competências e habilidades necessárias aos alunos para se apropriarem e aplicarem os conceitos da teoria dos fractais na descrição das formas e processos da natureza estamos propondo a teoria dos construtos pessoais (KELLY, 1970; BASTOS,1992). O Ciclo da Experiência de Kelly vem sendo aplicado de maneira exitosa em vários trabalhos realizados por alunos da Pós-Graduação em Ensino de Ciências e Matemática da UFRPE, sendo dois desses trabalhos realizado por alunos do nosso grupo de pesquisa, cujos resultados foram publicados em revista científica de circulação nacional e anais de congressos nacional (SOUZA et al., 2010; MEDEIROS et al., 2005).

A teoria dos construtos pessoais de KELLY (1970) tem como noções principais a idéia de construtos pessoais e o Ciclo da Experiência (CEK). Para Kelly, o homem analisa mundo através de seus construtos pessoais, assim, o conceito de geometria, nesta visão,é formado por um conjunto de construtos, tais como ponto, reta, plano, ângulos, dimensão, formas e outros. Contudo, cada construto tem um "lócus" de atuação; a cada momento, o sistema de construto de uma pessoa varia em função de sua permeabilidade (admissão ou não de novos elementos). É interessante, observar que o conceito de geometria de cada estudante varia ao admitir os novos elementos, tais como aqueles quecaracterizam as formas fractais, ou seja, dependência de escala, auto-similaridade e dimensão fracionária. A experiência é considerada, nesta teoria, como resultado das sucessivas construções e reconstruções da pessoa, ou seja, das mudanças do sistema de construtos operado pelo indivíduo durante um determinado processo. Desta maneira, o sistema de construção de um indivíduo varia quando ele sucessivamente constrói réplicas de eventos (KELLY, 1970), ou seja, as pessoas ajustam 
sua compreensão às realidades na medida da ocorrência de suas experiências. De acordo com Kelly, a aprendizagem ocorre segundo um ciclo que é determinado pelos seguintes momentos: Antecipação, Investimento, Encontro, Confirmação ou Refutação e Revisão Construtiva. Esse ciclo (FIG. 1) é denominado Ciclo da Experiência de Kelly (CEK).

FIGURA 1 - As cincos etapas do ciclo da experiência

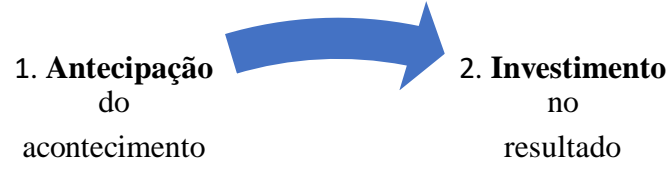

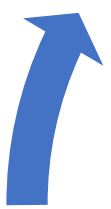

5. Revisão

Construtiva do

sistema de

construtos resultado

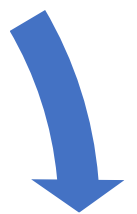

3. Encontro com

o acontecimento

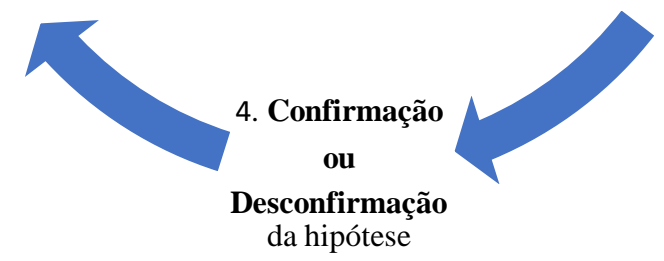

\section{ASPECTOS METODOLÓGICOS}

O Ciclo da Experiência de Kelly (CEK) é iniciado com a fase de antecipação que consiste em apresentar o objeto de estudo; neste momento, o aluno toma conhecimento do evento a ser vivenciado e constrói alguma réplica deste evento a partir da estrutura do seu sistema de construtos.

O conjunto de atividades realizadas nessa fase ocorreu em forma de dois encontros, com atividades individuais e cujo objetivo seria dar suporte ao aluno para prosseguir com a pesquisa. Para iniciar o primeiro contato com o objeto de estudo da pesquisa foi proposta uma atividade que consistia em observar as formas dos objetos que estavam dentro e fora da sala de aula. A idéia central dessa atividade era possibilitar o contato dos estudantes com as construções dos objetos feitos pelo homem e pela natureza.

Nas fases de investimento, encontro e confirmação foram discutidas as principais propriedades da geometria fractal, que são: dimensão fractal, auto-similaridade e complexidade. A abordagem de cada característica foi iniciada com a leitura e discussãode textos, apresentações de trabalhos versando sobre o tema, preparação e realização de atividades didáticas. Cada abordagem 
das características dos fractais foi seguida por análise dos alunos participantes. As realizações das atividades, foram iniciadas com a fase de investimento, na qual se busca o engajamento dos alunos no evento a ser vivenciado.

$\mathrm{Na}$ fase de encontro os alunos responderam aos questionamentos feitos pelo pesquisador, sobre quais seriam as características, observadas nos fractais nas atividades propostas. As conclusões dos alunos foram registradas no próprio texto da atividade. $\mathrm{Na}$ fase de confirmação, após os consensos dos alunos, o pesquisador conduziu uma discussão com os três alunos, na qual socializaram suas conclusões, as características observadas foram citadas de forma relevantes e os aspectos equivocados foram corrigidos pelo pesquisador.

Após estas etapas, os alunos passam à fase da revisão construtiva. Na revisão construtiva, que é a fase na qual o indivíduo toma conhecimento das mudanças cognitivas operadas no fechamento do Ciclo da Experiência, foram analisadas as respostas dos questionários de três alunos, com o objetivo de investigar se houve mudança no sistema de construtos desses alunos após a intervenção didática.

\section{EXPERIMENTOS DIDÁTICOS}

$\mathrm{Na}$ intervenção didática, durante o Ciclo da Experiência foram realizados seis experimentos didáticos, quatro deles sugeridos por Barbosa (2002). Será descrita neste texto somente um experimento didático. Outros experimentos didáticos podem ser encontrados em Barbosa (2002). O que estamos interessados aqui é mostrar como analisar um experimento a luz do CEK e, portanto, a análise de um único experimento atende a nossa proposta.

Descrição do Experimento didático : Trabalhando com a geometria da natureza.

Neste experimento foi solicitado que os alunos

1) Identificassem e listassem alguns objetos presentes na sala de aula, associando assuas formas às das figuras geométricas euclidianas conhecidas.

2) Repetissem a observação, tomando agora como base áreas livres que os alunos estão familiarizados (parques, jardins, quintais, etc.), associando, mais uma vez, as suas formas, aproximando-as de formas geométricas euclidianas conhecidas.

\section{RELATO DOS DADOS DO EXPERIMENTO.}

Os resultados desta investigação são mostrados no quadro abaixo: 
Quadro1 - Comparação feita pelos dos alunos dos objetos da sala de aula em relação aosobjetos construídos pela

\begin{tabular}{|l|l|l|}
\hline Ambiente & Objetos Observados & Figuras Associadas \\
\hline $\begin{array}{l}\text { Sala de } \\
\text { Aula }\end{array}$ & Quadro Negro & Retângulo \\
\hline & Lata de Lixo & Cilindro \\
\hline & Armário & Paralelepípedo \\
\hline & Assento da Mesa & Quadrado \\
\hline Fora da & Tampo da Fechadura & Círculo \\
\hline $\begin{array}{l}\text { Sala de } \\
\text { Aula }\end{array}$ & Favo de Mel & Hexágono \\
\hline & Miolo das Flores & Círculo \\
\hline & Tronco da Árvore & Cilindro \\
\hline & Frutas (laranja, maçã, uva) & Esferas \\
\hline & Estrela do Mar & Polígono Estrelado \\
\hline & Gota & Retas e Círculos Concorrentes \\
\hline & Olhos dos Animais & Ovais \\
\hline
\end{tabular}

Após a simples listagem os alunos constataram a imperfeição das formas geométricas encontradas na natureza e expressaram através de frases como as que seguem: ... Os fractais aparecem nas irregularidades próprias dos objetos da natureza" ou, ainda ... As formas euclidianas são criadas pelo homem, são fruto de idealizações.

Atingido o objetivo primeiro da atividade que foi a identificação das formas fractais da natureza, foi realizado o seu fechamento ressaltando a importância da descoberta que eles próprios evidenciaram: a necessidade de uma outra geometria que descreva os objetos da natureza. Além disso, foi ressaltada a característica de auto-similaridade dos fractais, exemplificada pela couve-flor, os brócolis e os galhos de arvores.

\section{ANÁLISES DOS DADOS COLETADOS}

Como mencionado anteriormente, as informações foram coletadas através de dois instrumentos: o questionário diagnóstico e os registros dos consensos dos três alunos durante a aplicação das atividades.

\section{DIAGNÓSTICO: ANÁliseS DOS PRÉ E PÓS-TESTES.}

As análises dos pré e pós-testes constituíram as principais fontes de informações sobre a estrutura cognitiva dos alunos em relação às características dos fractais estudados nas abordagens da intervenção didática. A tabela abaixo mostra, de maneira categorizada, as respostas dos três alunos participantes de todas as fases da pesquisa, antes e após a intervenção didática. 
Quadro 2 - Respostas ao questionário diagnóstico, antes e após a intervenção.

\begin{tabular}{|c|c|c|}
\hline Pergunta & $\begin{array}{l}\text { Pré-teste } \\
\text { Alunos (A, B e C) } \\
\text { Antes da intervenção }\end{array}$ & $\begin{array}{l}\text { Pós-Teste } \\
\text { Alunos (A, B e C) } \\
\text { Após a intervenção }\end{array}$ \\
\hline $\begin{array}{l}\text { O que significa geometria para } \\
\text { você? }\end{array}$ & $\begin{array}{l}\text { Responderam } \quad \text { dando } \\
\text { ênfase a formas e } \\
\text { medidas. }\end{array}$ & $\begin{array}{l}\text { Responderam de forma coesa, } \\
\text { todos citaram, além das formas } \\
\text { conhecidas, várias estruturas } \\
\text { fractais }\end{array}$ \\
\hline $\begin{array}{l}\text { Que tipos de geometria você } \\
\text { conhece? }\end{array}$ & $\begin{array}{l}\text { Citaram as geometrias } \\
\text { euclidianas (Plana, } \\
\text { Espacial e Analítica). }\end{array}$ & $\begin{array}{l}\text { Além das já citadas no pré-teste, } \\
\text { todos citaram a geometria } \\
\text { Fractal. }\end{array}$ \\
\hline \begin{tabular}{llr} 
Das geometrias & \multicolumn{2}{c}{ que você } \\
conhece, cite & exemplos de \\
construções & de & figuras \\
geométricas? & &
\end{tabular} & \begin{tabular}{|lrr} 
Citaram & \multicolumn{2}{c}{ construções } \\
geométricas & de figuras \\
euclidianas, & tais como \\
triângulo &, & circulo, \\
cilindro, etc. & &
\end{tabular} & $\begin{array}{l}\text { Citaram construções da } \\
\text { geometria euclidiana e algumas } \\
\text { estruturas fractais. }\end{array}$ \\
\hline $\begin{array}{l}\text { Qual a utilidade prática da } \\
\text { geometria na sua vida? }\end{array}$ & $\begin{array}{l}\text { Responderam que a } \\
\text { geometria serve para } \\
\text { construir os utensílios do } \\
\text { cotidiano das pessoas. }\end{array}$ & $\begin{array}{lll}\begin{array}{l}\text { Responderam } \\
\text { construções }\end{array} & \text { salientando } \\
\text { naturealizadas } & & \text { as } \\
\text { nela }\end{array}$ \\
\hline $\begin{array}{l}\text { Você acha que as geometrias que } \\
\text { você conhece são capazes de } \\
\text { descrever as formas construídas } \\
\text { pelo homem? }\end{array}$ & Toc & $s$ respond \\
\hline $\begin{array}{l}\text { E as formas construídas pela } \\
\text { natureza, podem ser também } \\
\text { descritas pelas geometrias que } \\
\text { você conhece? }\end{array}$ & $\begin{array}{l}\text { Responderam } \\
\text { adequadamente } \\
\text { relação aos objetos } \\
\text { construídos pelo homem } \\
\text { e equivocadamente em } \\
\text { relação aos objetos } \\
\text { construídos pela natureza. }\end{array}$ & $\begin{array}{l}\text { Responderam adequadamente em } \\
\text { relação aos objetos construídos } \\
\text { pelo homem e também em } \\
\text { relação aos objetos construídos } \\
\text { pela natureza. }\end{array}$ \\
\hline $\begin{array}{l}\text { O que você } \\
\text { dimensão entende por } \\
\text { geometria? }\end{array}$ & $\begin{array}{l}\text { Responderam com base } \\
\text { na geometria euclidiana. }\end{array}$ & $\begin{array}{l}\text { Responderam de uma maneira } \\
\text { mais geral, utilizando tanto a } \\
\text { geometria euclidiana como } \\
\text { fractal. }\end{array}$ \\
\hline $\begin{array}{l}\text { Dê um exemplo de } \\
\text { dimensão nas geometrias } \\
\text { que você conhece. }\end{array}$ & $\begin{array}{l}\text { Citaram exemplos de } \\
\text { figuras geométricas } \\
\text { planas e espaciais com } \\
\text { as devidas dimensões. }\end{array}$ & $\begin{array}{l}\text { Citaram exemplos de figuras } \\
\text { geométricas planas e espaciais, } \\
\text { porém citaram a possibilidade } \\
\text { da existência de dimensão } \\
\text { fracionária. }\end{array}$ \\
\hline
\end{tabular}

\section{ANÁLISES DAS RESPOSTAS DOS ALUNOS}

As transcrições das respostas dos alunos são apresentadas de forma resumida no quadro 3 para os questionamentos sobre a característica auto-similaridade. No quadro 4 sobre a característica complexidade, onde eles discutiram as formas e processos que a natureza constrói seus objetos e para a característica dimensão fractal o quadro 5, na mesma ordem em que foram coletados. $\mathrm{Na}$ análise procurou-se identificar os aspectos relacionados às características da geometria fractal explicitados pelos alunos.

Essas respostas foram registradas nas etapas investimento, encontro e confirmação do Ciclo da Experiência. É importante observar que as propriedades fractais enfocadas foram às seguintes: auto-similaridade, complexidade e dimensão fractal. 
QUADRO 3 - Respostas dos alunos ao questionamento sobre Auto-similaridade

\begin{tabular}{|l|l|}
\hline Pergunta & $\begin{array}{l}\text { Em relação à característica auto- similaridade, o que ficou entendido } \\
\text { por você no que se refere às construções da natureza? }\end{array}$ \\
\hline ALUNO A & $\begin{array}{l}\text { Observei que os objetos e construções da natureza obedecem a processos } \\
\text { auto-similares, tanto de natureza euclidiana como de natureza fractal, } \\
\text { posso indicara estrela do mar, que apesar de ser um ser um objeto } \\
\text { natural, podemos reproduzi-lo euclidianamente como foi mostrado no } \\
\text { filme Donald no País da Matemágica. }\end{array}$ \\
\hline ALUNO B & $\begin{array}{l}\text { As construções feitas pelo homem podem ser ditas auto-semelhantes, } \\
\text { mas não auto-similar, pois auto-similaridade significa uma parte pode } \\
\text { representar o todo, já na semelhança as figuras não podem ser quebradas, } \\
\text { e suas dimensões se mantêm e no caso da auto-similaridade depende do } \\
\text { fator de escala. }\end{array}$ \\
\hline ALUNO C & $\begin{array}{l}\text { Meu entendimento sobre auto-similaridade foi que os processos e } \\
\text { construções da natureza obedecem a esta característica, dando a entender } \\
\text { que todos os processos são auto - similares, cito como exemplo a costa } \\
\text { da Inglaterra apresentada num dos slides projetados durante a exposição } \\
\text { do professor. }\end{array}$ \\
\hline
\end{tabular}

QUADRO 4- Respostas dos alunos a característica Complexidade

\begin{tabular}{|l|l|}
\hline Pergunta & $\begin{array}{l}\text { Seu entendimento sobre complexidade contempla ageometria } \\
\text { fractal? }\end{array}$ \\
\hline ALUNO A & $\begin{array}{l}\text { Sim, as atividades realizadas na pesquisa mostraram que os processos e } \\
\text { construções dos objetos da natureza são complexos, apesar de suas leis de } \\
\text { formações serem simples. }\end{array}$ \\
\hline ALUNO B & $\begin{array}{l}\text { Sim, meu entendimento sobre complexidade mudou, pois achava que } \\
\text { complexo significava difícil, mas após o entendimento da geometria } \\
\text { fractal compreendi que complexo não é complicado, mas sim que a partir } \\
\text { de processos simples (iterações) podemos gerar estruturas complexas. }\end{array}$ \\
\hline ALUNO C & $\begin{array}{l}\text { Meu entendimento sobre complexidade ficou um pouco confuso, pois } \\
\text { achava que complexidade seria complexo mesmo, mas após a } \\
\text { apresentação das oficinas pude perceber que complexo seria apenas como } \\
\text { os objetos que são gerados pela natureza. }\end{array}$ \\
\hline
\end{tabular}

QUADRO 5- respostas dos alunos ao questionamento sobre Dimensão fractal Após a introdução do conceito de fractal, seu conceito sobre dimensão mudou?

Pergunta

ALUNO A

Sim, o conceito de dimensão que conhecia mudou radicalmente, pois pude perceber que existem outras dimensões, que elas estão presentes em todos os processos e objetos apresentados nas atividades e discussões que versavam sobre geometria da natureza, um dos exemplos que me chamou atenção foi à Esponja de Menger.

ALUNO B Meu conceito sobre dimensão mudou, como a geometria fractal abriu minha mente, percebi que os processos e construções feitas pela natureza, são diferentes daqueles realizados pelo homem para suas construções.

ALUNO C Fiquei confuso para entender a dimensão fracionária, pois só 
conseguia enxergar a dimensão fechada (euclidiana), mesmo realizando as atividades e enxergando a dimensão fracionária, fiquei surpreso, por que, como estávamos cegos a ponto de não perceber esta geometria proposta por Benoit Mandelbrot. Acho que precisamos de mais atividades e exemplos para preencher mais ainda as lacunas (ou bloqueios) que existem sobre este novo conceito de dimensão.

A análise dos quadros 3, 4 e 5 mostra: que o aluno A percebeu as várias propriedades dos fractais, tais como auto-similaridade, complexidade e dimensão fractal; que o aluno B compreendeu as propriedades auto-similaridade, complexidade e dimensão fractal e também usou a idéia de iteração na construção dos objetos fractais; o aluno C entendeuo conceito de auto-similaridade, porém teve dificuldade na compreensão dos conceitos de complexidade e dimensão fractal.

\section{CONSTRUTOS IDENTIFICADOS NAS FASES DE PRÉ E PÓS-TESTES}

Inicialmente buscou-se identificar quais os construtos levantados pelo aluno A na fase antecipação do ciclo, de modo a compará-los com os construtos levantados na fase de revisão construtiva, que foi o último momento da intervenção didática. Estas fases podem ser consideradas com etapas de pré e pós-teste. Os construtos levantados nestes momentos são apresentados no quadro abaixo:

\begin{tabular}{|l|l|}
\hline \multicolumn{2}{|c|}{ Quadro 6- construtos levantados pelos alunos } \\
\hline PRÉ-TESTE & PÓS-TESTE \\
\hline Dimensão & Dimensão fractal \\
\hline Área & Auto similaridade \\
\hline Volume & Complexidade \\
\hline Diagonais & Iterações \\
\hline Lados & Propriedades processos construção \\
\hline & natureza \\
\hline Comprimento & Objetos natureza \\
\hline Adimensional & Dimensão euclidiana \\
\hline Inexistência de área & Construções simples \\
\hline Inexistência de volume & Processo simples \\
\hline & Propriedades euclidianas \\
\hline Inexistência de diagonais & \\
\hline & \\
\hline Inexistência de lados & Objetos construídos pelos homens \\
\hline \hline
\end{tabular}

Analisando esta tabela, percebe-se que no pré-teste o aluno A citou 12 construtos no total, podemos observar que os construtos relacionados, intuitivamente já mostravam a dificuldade em enxergar a geometria da natureza e suas propriedades ou características. Já no pós-teste esta proporção está sensivelmente alterada: de um total de 11 construtos, 
7 são relacionados à geometria fractal e suas características, enquanto 4 deles relacionam-se a geometria euclidiana, como, por exemplo, figuras planas que possuem dimensões inteiras.

A análise do quadro 6 para o aluno aluno A mostra que no pré-teste o estudanteelaborou a sua concepção de geometria baseado somente em figuras euclidianas. Isto seevidência pelos construtos, tais dimensão, área, volume, diagonais, lados e comprimentoe todos eles relacionados com figuras euclidianas (reta, ponto, círculo, losango e cubo). Portanto, sua concepção de geometria não permitia uma descrição geométrica adequadapara os objetos da natureza. No pós-testes, vários novos construtos podem ser observados, tais como dimensão fractal, auto-similaridade, complexidade, iterações eobjetos da natureza. Isto mostra que a intervenção didática permitiu uma evolução noconceito de geometria do aluno, incluindo na sua concepção vários construtos relacionados a geometria fractal. Esta evolução conceitual possibilitou que o estudantedescrevesse de maneira adequada os objetos construídos pela natureza.

As respostas dos alunos $\mathrm{B}$ e $\mathrm{C}$ foram analisadas do mesmo modo que o aluno A. A análise das falas dos três alunos nos permitiu concluir que: i. os estudantes ampliaram seus construtos pessoais como resultado da intervenção didática proposta no trabalho; ii.é possível introduzir conceitos abstratos como dimensão fractal, auto-similaridade ecomplexidade, no ensino médio, usando-se procedimentos e técnicas adequadas. 


\section{BIBLIOGRAFIA}

BARBOSA, R. M.. Descobrindo a Geometria Fractal - para a sala de aula. Belo Horizonte: Autêntica, 2002.

BARNSLEY, M.F. Fractals Everywhere. Cambridge. Academic Press, 1993

BASSINGTHWAIGHTHE, J.B., LIEBOVITCH, L.S. WEST, B.J. Fractal Physiology. New York: Oxford University Press, 1994

BASTOS, H. F. B.N. Changing teacher's pratice: towards a constructivist methodologyof physics toaching, 1992, Tese de doutorado, University of Surrey, Inglaterra.

BRASIL, Ministério da Educação. Secretaria de Educação Média e Tecnológica. Ministério de Educação e Cultura. PCN+ Ensino Médio: Orientações Educacionais Complementares aos Parâmetros Curriculares Nacionais. Brasília: SEMTEC, 2002.

FEDER, J. Fractals. New York. Plenum Press, 1988

JANOS, M. Geometria Fractal. Rio de Janeiro: Ciência Moderna, 2008

KELLY, G.A. A Brief Introduction to Personal Construct Theory. In Baunister. Ded. Perspectives in Personal Construct Theory. London: Academic Press, 1970.

LIEBOVITCH, L.S. Fractals and Chaos Simplified for the Life Sciences. New York: Oxford University Press, 1998.

MANDELBROT, B. OBJECTOS FRACTAIS: FORMA, ACASO E...2ªD.(1998) editora: Gradiva. coleção: CIENCIA ABERTA - Vol.

MANDELBROT, B. The Fractal Geometry of Nature. 3. ed. New York: W.HFreeman, 1983.

MEDEIROS, R.M.H., NOGUEIRA, R.A. FERREIRA, H.S. A investigação das relações estabelecidas por licenciandos em física entre a estrutura da matéria e as propriedades macroscópicas dos materiais. Anais do V Enscontro Nacional de Pesquisa em Educação em Ensino de Ciências, 2005

SILVA, F.H., SIMADA , F.K.S., LUCCAS, S. O Ensino de Fractais no Ensino Fundamental I: um estudo nos documentos oficiais do Paraná. Anais do Encontro Paranaense de Educação Matemática, 2017

SOUZA ,P.F.L., BASTOS, H.F.B.N., COSTA,E.B., NOGUEIRA, R.A. Pensamento transdisciplinar: uma abordagem para compreensão do princípio da dualidade da luz. Revista Brasileira de Ensino de Física. 32 (2), p.2402, 2010

SULEIMAN, A.R. Fractais: Possibilidades Pedagógicas na Escola Básica. Ensino de Matemática em Debate 2019. Doi: https://doi.org/10.23925/2358-4122.2019.V6ilp61-83. 